\title{
Prosthetic materials for treating posterior vaginal wall prolapse and rectocele - own experience
}

\author{
Honorata Stadnik, Tomasz M. Kościński \\ H. Swiecicki Clinical Hospital, Poznan, Poland
}

\begin{abstract}
Objectives: This report describes results of posterior vaginal wall prolapse and rectocele treatment performing tension free reconstruction method with polypropylene mesh implantation.

Material and methods: In years 2001 to 20015, 71 female patients in age of 42-82 years were surgically treated. Besides difficult emptying they complained of feeling of heaviness in the pelvis (38\%) and dyspareunia (16.9\%). Defecography and magnetic resonance proved the presence of rectocele in $84.5 \%$, enterocele in $38 \%$, descending perineum in $28.2 \%$, genital organ prolapse in $23.9 \%$, and rectal prolapse in $22.5 \%$ cases. 37 patients with defects of low location have undergone implantation of prosthetic material from vaginal approach. In cases of high location and genital organ prolapse abdominal approach was done.

Results: Permanent reconstruction of the rectovaginal septum has been achieved in 70 patients (98\%). Symptoms of dyschesia, pelvic plain, heavy straining were persisted in 4 patients (10.3\%). 3 cases of mash erosions were diagnosed. One patient was reoperated. Among 6 other patients who needed futher surgical treatment only one was reoperated because of vaginal prolapse. $81.7 \%$ of patients was satisfied with their treatment.

Conclusion: Using prosthetic materials in pelvic floor defects treatment is characterized by high efficacy and low complication percentage.
\end{abstract}

Key words: pelvic fascia anatomical defects, rectocele, using prosthetic materials

Ginekologia Polska 2016; 87, 11: 729-732

\section{INTRODUCTION}

Damage in the recto-vaginal septum and weakness of the fasciomuscular pelvic floor structures constitute the main causes of the pathomechanism of complex pathologies, including rectocele and vaginal prolapse. The long-lasting process of disease development leads to the disappearance of suitable for reconstruction tissues. Surgical treatment in such cases is challenging and associated with the risk for early recurrence, with a high rate of postoperative dyspareunia [1]. The use of highly advanced imaging methods allows for the diagnosis of the following coexisting pathologies: excessive atony and pelvic floor descend, enterocele, internal intussusception, and rectal prolapse. The use of prosthetic materials has brought a new quality to the surgical treatment of complex anatomical disorders. Polypropylene meshes are used for the reconstruction of the fasciomuscular structures and as a scaffolding for the attach- ment of the prolapsing organs. The aim of this study was to evaluate the efficacy of surgical treatment of rectovaginal septal defects by performing tension-free reconstruction with polypropylene mesh and the tolerance of prosthetic materials by the body.

\section{MATERIAL AND METHODS}

Prosthetic materials for treating rectovaginal septal damages were used in 71 female patients, operated between 2001 and 2015. Patient age ranged between 42 to 82 years (mean: 62 years).

Informed consent was obtained from all patients. The study observed the guidelines of the declaration of Helsinki on Biomedical Research from 1964. MR scans and defecography were performed to visualize all anatomical defects. Measuring the distance between the anterior rectal wall and the most protruding point of the rectocele 
Table1. Rectocele symptomatology

\begin{tabular}{|l|c|c|}
\hline & N & $\%$ \\
\hline Obstructed defecation & 43 & 60 \\
\hline Feeling of a mass in vagina, prolapsing vagina & 27 & 38 \\
\hline Urinary incontinence & 5 & 7 \\
\hline Fecal incontinence & 8 & 11.2 \\
\hline Dyspareunia & 12 & 16.9 \\
\hline
\end{tabular}

Table 2. Pelvic floor pathologies accompanying rectocele

\begin{tabular}{|l|c|c|}
\hline & N & $\%$ \\
\hline Rectocele & 60 & 84.5 \\
\hline Enterocele & 27 & 38 \\
\hline Descending perineum & 20 & 28.2 \\
\hline Prolapse of vagina/uterus & 17 & 23.9 \\
\hline Rectal prolapse & 16 & 22.5 \\
\hline Cystocele & 12 & 16.9 \\
\hline Anismus & 3 & 4.2 \\
\hline Uterine myoma & 1 & 1.4 \\
\hline
\end{tabular}

increased the sizes of rectoceles, which ranged from 2.5 to $8 \mathrm{~cm}$ (mean: $4 \mathrm{~cm}$ ). The sizes of the enterocele ranged from 3 to $9 \mathrm{~cm}$ (mean: $4.8 \mathrm{~cm}$ ). MR scans diagnosed the pelvic floor descent to range from 3.5 to $4.5 \mathrm{~cm}$ (mean: $3.8 \mathrm{~cm}$ ).

Overall, $60 \%$ of the patients experienced great difficulty with bowel movement, incurable with conservative treatment (Table 1). The feeling of "burden" of the obstructing mass in the vagina or the pelvic floor area was reported by 27 of the women (38\%). Stool incontinence was reported by 8 patients (11.2\%), and stress urinary incontinence by 5 women (7\%). Dyspareunia was a significant complaint in 12 patients (16.9\%). Rectal prolapse was detected in $16 \mathrm{fe-}$ males (22.5\%), with 4 of them experiencing postoperative prolapse recurrence (Table 2). Excessive atony and pelvic floor descent were diagnosed in 20 patients (28.2\%). The most common accompanying pathology was enterocele - confirmed in $38 \%$ of the patients. The women had undergone various surgical operations (between 1 and 4) in their pelvic floor area (Table 3). In 13 patients, the recto-vaginal septal defects proved recurrent in character. In 9 cases the recurrence appeared after posterior vaginoplasty and in 4 cases after the Sullivan-Sarles trans-anal approach.

All women deemed eligible for mesh reconstruction of the rectovaginal septum had given one to five births, usually two. The episiotomy rate was $80 \%$. Seven of the women had given instrument-assisted births (either forceps or ventouse).

Postoperative satisfaction - quality of life (QoL) - was evaluated 6 months after the surgery using a questionnaire.
Table 3. Surgeries performed before rectocele mesh repair

Hysterectomy 20

Posterior colporaphy 9

\begin{tabular}{l|l|l} 
Abdominal rectopexy & 4
\end{tabular}

Sigmorectal resection $\quad 1$

Uteropexy 1

Bladder neck mesh suspension $\quad 2$

Longo anopexy

Thiersch procedure $\quad 1$

Sullivan-Sarles rectocele repair $\quad 4$

Anal fistula excision $\quad 2$

Perineoplasty 3

Improvement in QoL was based on the comparison with the initial symptoms, anorectal functionality, bowel movement ease, sexual performance, and urination trouble.

This is a prospective cohort study.

\section{Surgical treatment methods}

Location and size of the rectocele, as well as the presence of other pathologies in the pelvic floor structures and organs determined the choice of the method. In 37 of the patients the rectocele were located in either the lower or the middle section of the rectovaginal septum. These patients were operated trans-vaginally. Due to the coexisting complex pathologies, it was necessary to perform the surgery via the abdominal approach in 16 patients, and in further 18 patients these pathologies were treated using the combined abdominal and transvaginal approach.

Prosthetic materials were used for tension-free reconstruction of the rectovaginal septum.

The size of the mesh in each case was tailored individually, depending on the size of the loss in the septum.

The mesh was then sewn to the puborectal muscle borders, while its lower part was attached to the perineal body structures. The upper part of the mesh was stitched to the remaining fibers of the Denonvilliers' fascia. Perimedial approximation of splayed puborectal muscles was achieved with tension-free reconstruction of the rectovaginal septum.

In abdominal approach, the pelvic floor peritoneum was opened wide and the rectovaginal space was dissected to the level of peritoneal tissues. By opening the presacral space wide, we could expose the spot for the mesh attachment, and also reach the level of levator ani fascia from both sides. In patients suffering from the coexisting rectal prolapse, it was necessary to reach its lateral ligaments (Figure 1).

After the polypropylene mesh was tailored as needed to properly fill the gap in the septum (U shape, for example), it was inserted and placed on the pelvic floor. The lower border 


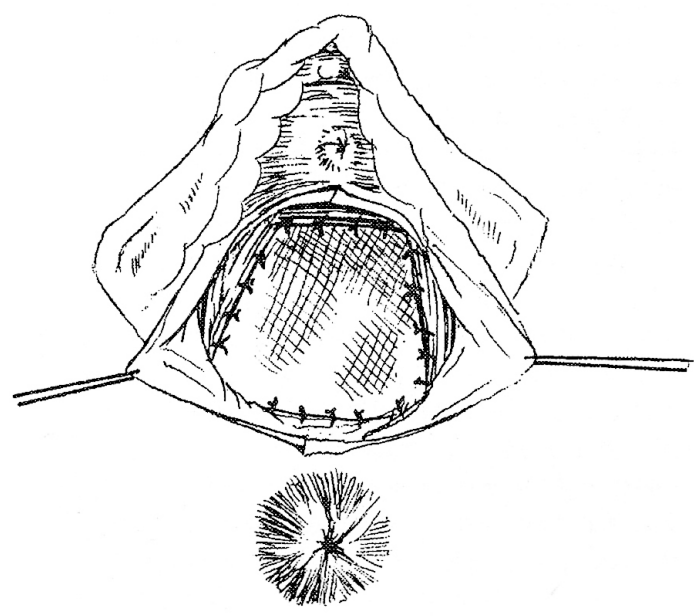

Figure 1. Mesh attachment in the pelvic floor

of the mesh was stitched to the perineal body and - bilaterally - to the ischio-coccygeal fascia. The lateral parts of the prosthetic material were attached above the loss in the Denonvillers' fascia with several non-absorbable stitches.

The upper ends of the mesh were suspended on the presacral fascia or periosteum of the S1 and S2 vertebrae. Prolapsing vaginal stump and rectum were attached to the central part of the mesh.

The surgeries performed from the abdominal-perineal approach allowed for a better access to the lower part of the recto-vaginal septal defect and sewing the mesh appropriately under visual control.

Mean surgery time was $110 \mathrm{~min}$. for the vaginal approach, $140 \mathrm{~min}$. for the abdominal approach, and $160 \mathrm{~min}$. for the abdominal-vaginal approach. Mean hospitalization time was 4 days for the vaginal approach, and 6 days (5-19) for surgeries involving opening of the abdomen.

\section{RESULTS}

The results of the treatment were assessed 6 months after the procedure. Permanent reconstruction of the rectovaginal septum has been achieved in $98 \%$ of the patients. One woman operated via the vaginal approach experienced a recurrence. Dyschezia persisted in 4 patients (Table 4). Three patients operated by laparotomy complained of pain in the lower abdomen. One of them was MR-scanned and diagnosed with fibrous infiltration in the mesh area, subsequently cured with an antibiotic therapy. There was no need to remove the implants from any other patient. Three cases of erosion of the polypropylene meshes toward the vagina were small in size, and only required cutting off of the protruding fragments. In 1 case, the exposed part of the mesh was covered with a repositioned flap of mucous membrane. Nine patients had to be reoperated. Mean time
Table 4. Postoperative complications

\begin{tabular}{|c|c|c|c|}
\hline & $\begin{array}{l}\text { Abdominal } \\
\text { approach }\end{array}$ & $\begin{array}{l}\text { Abdominovaginal } \\
\text { approach }\end{array}$ & $\begin{array}{l}\text { Vaginal } \\
\text { approach }\end{array}$ \\
\hline & $N=16$ & $N=18$ & $N=37$ \\
\hline $\begin{array}{l}\text { Rectocele } \\
\text { recurrence }\end{array}$ & - & - & 1 \\
\hline $\begin{array}{l}\text { Flaccidity of anal } \\
\text { sphincters }\end{array}$ & 1 & - & - \\
\hline $\begin{array}{l}\text { Obstructed } \\
\text { defecations }\end{array}$ & 2 & 1 & 1 \\
\hline Rectal tenesmus & - & 1 & - \\
\hline Cystocele & 1 & 1 & - \\
\hline Pelvic pain & 2 & - & 1 \\
\hline Abdominal hernia & - & $1 \mathrm{R}$ & - \\
\hline Bowel obstruction & $2 \mathrm{R}$ & - & - \\
\hline Anal fistula & - & - & 1 \\
\hline $\begin{array}{l}\text { Postoperative } \\
\text { bleeding }\end{array}$ & - & 1 & $1 \mathrm{R}$ \\
\hline Anal late bleeding & - & - & 1 \\
\hline $\begin{array}{l}\text { Wound } \\
\text { suppuration }\end{array}$ & - & - & 1 \\
\hline Mesh erosion & - & 1 & $2 \mathrm{R}$ \\
\hline Urinary urgency & - & $1 \mathrm{R}$ & - \\
\hline Prolapse of vagina & - & $1 \mathrm{R}$ & - \\
\hline $\begin{array}{l}\text { Deep pelvic } \\
\text { fibrous infiltration }\end{array}$ & 1 & - & - \\
\hline $\begin{array}{l}\text { Anal mucosal } \\
\text { prolapse }\end{array}$ & 1 & - & $1 \mathrm{R}$ \\
\hline $\begin{array}{l}\text { Neurological } \\
\text { disorders }\end{array}$ & 2 & 1 & - \\
\hline
\end{tabular}

$\mathrm{R}$ - reoperation

\section{Table 5. Satisfaction survey of patients}

\begin{tabular}{|l|c|c|c|}
\hline & $\begin{array}{c}\text { Vaginal } \\
\text { approach }\end{array}$ & $\begin{array}{c}\text { Abdominal } \\
\text { approach }\end{array}$ & $\begin{array}{c}\text { Abdominovaginal } \\
\text { approach }\end{array}$ \\
\hline N=37 & $\mathbf{N = 1 6}$ & $\mathbf{N = 1 8}$ \\
\hline Very satisfied & 21 & 6 & 10 \\
\hline Satisfied & 14 & 5 & 6 \\
\hline Not satisfied & 1 & 2 & 1 \\
\hline $\begin{array}{l}\text { Satisfying } \\
\text { sexual life }\end{array}$ & 14 & 3 & 5 \\
\hline
\end{tabular}

between the first operation and reoperation was 138 days (1 day to 11 months). Except for one patient, whose vaginal stump detached from the prosthesis eight months after the surgery, none of these re-operations was directly connected to the mesh implantation.

Mean length of follow-up was 34 months (6 to 93 months). Six months after surgery, the patients evaluated their degree of satisfaction with their treatment (Table 5). None of the 
women conceived during the follow-up. Twenty-two of them (31\%) could have sexual intercourses.

One patient died because of the Ogilvie syndrome.

\section{DISCUSSION}

Vaginal birth, especially prolonged or hastened labor, as well as instrument-assisted births without any doubt cause damage to the fascia, ligament and muscle structures of the pelvic floor, as well as its denervation $[2,3]$.

Rectovaginal wall is the most common anatomical structure which is damaged in the process. It is a component of a wider fibro-areolar layer which connects with the vaginal wall and levator ani fasciae at the perineal body level [1, 4-6]. Damage in the rectovaginal septum results in rectocele, which is believed to be the main causes of dyschezia. Considerable size of the anatomical loss, as well as lowered quality of the tissues may render a successful reconstruction of the septum impossible $[7,8]$.

Grafting of prosthetic materials has advanced rectocele reconstruction to a new level. Nevertheless, implantation of a non-absorbable polypropylene mesh may lead to its erosion, invoke a feeling of foreign mass in the space between the vagina and the rectum, as well as become the site of inflammation. Various authors have estimated the occurrence of prosthetic material erosion, mainly through the vaginal wall, at $0-20 \%$ of the operated patients $[4,6$, 9-12]. Its surgical repair is seldom necessary. Elmer et al., performed this in only $2.8 \%$ of the patients [12]. It is also important to maintain rigorous aseptic procedures during the surgery.

Rectocele located in the upper part of the septum, especially accompanied by other pathologies as enterocele, rectal prolapse, uterine and vaginal prolapse, or descending perineum, require abdominal implantation of the prosthetic material.

The abdominal-vaginal approach allows not only for a precise repair of the rectovaginal septal loss, but also secure stitching of the mesh to the perineal body structures and lower parts of the levator ani. In that way, the pelvic floor obtains strong support, which prevents its further sinking and widening of the gap between the anal levators. Stretching over the rectovaginal space and attached to the sacral bone, the mesh forms a framework, to which prolapsing organs of the pelvis may be stitched. In their treatment of prolapse, Sullivan et al., attach the lower part of the Marlex mesh to the perineal body using a special needle, without opening the vaginal vestibule [5]. However, it is not possible to fix the accompanying rectocele with this method.

Collopy and Barham employed two separate approaches in their method of treating rectocele with a coexisting prolapse of the pelvic organs: abdominal approach for poly- propylene mesh colporectopexy; and vaginal approach for anterior and posterior colporrhaphy [13]. They observed vagina prolapse in 9 out of 89 patients treated with this method.

Permanent reconstruction of the rectovaginal septum and remission of rectocele has been achieved in almost all patients in this study.

Tension-free methods of treating rectocele greatly reduce the risk of postoperative dyspareunia. This complication was successfully avoided in 71 patients, operated by different modifications of the technique. Lechaux et al., achieved similar results in patients who had their prosthetic material implanted transperineally [4]. Other authors rate the risk of postoperative dyspareunia between 1 to $21 \%$ of patients $[10,11,14,15]$. A very high rate of satisfied or very satisfied patients seems highly promising.

In conclusion, it is important to emphasize that prosthetic materials used in treatment of rectocele and other complex anatomical defects of the pelvic floor are characterized by good tolerance, high durability and relatively low rate of complications and other undesired side effects.

\section{REFERENCES}

1. Nieminen K, Hiltunen KM, Laitinen J, Oksala J, Heinonen PK. Transanal or vaginal approach to rectocele repair: a prospective randomized pilot study. Dis Colon Rectum. 2004, 47, 1636-1642.

2. Snooks SJ, Swash M, Henry MM, Setchell M. Risk factors in childbirth causing damage to the pelvic floor innervation. Int J Colorectal Dis. 1986, 1, 20-24.

3. Sultan $\mathrm{AH}$, Stanton SJ. Occult obstetric trauma and anal incontinence. Eur J Gastroenteral Hepatol. 1997, 9, 423-427.

4. Lechaux JP, Lechaux D, Bataille P, Bars J.Transperineal repair of rectocele with prosthetic mesh. A prospective study. Annals de Chirurgie. 2004, 129, 211-217.

5. Sullivan ES, Longaker CJ, Lee PYH. Total pelvic mesh repair. A ten-year experience. Dis Colon Rectum. 2001, 44, 857-863.

6. De Vita D, Araco F, Gravante G, Sesti F, Piccione E. Vaginal reconstructive surgery for severe pelvic organ prolapses: a "uterine-sparing"technique using polypropylene prostheses. Eur J Obstet Gynecol Reprod Biol. 2008, 139, 245-251.

7. Kahn MA, Stanton SL. Techniques of rectocele repair and their effects on bowel function. Int Urogynecol J. 1998, 9, 37-47.

8. Azanjac B, Jorovic M. Transperineal repair of recurrent rectocele using polypropylene mesh. Tech Coloproctol. 1999, 3, 39-41.

9. Escribano J, Furio MJ, Cuesta JA, Garcia FJG, Olivas JLC. Transvaginal mesh perineal repair of the rectovaginal septum in the treatment of rectocele and enterocele. Outcomes in 77 patients. Cir Esp. 2006, 79, 108-113.

10. Tayrac R, Picone O, Chauveaud-Lambling A, Fernandez H. A 2-year anatomical and functional assessment of transvaginal rectocele repair using a polypropylene mesh. Int Urogynecol J. 2006, 17, 100-105.

11. Shak DK, Paul EM, Rastinehad AR, Eisenberg ER, Badlani GH. Short-term outcome analysis of total pelvic reconstruction with mesh: the vaginal approach. J Urol. 2004, 171, 261-263.

12. Elmer C, Altman D, Eugh ME, Axelsen S, Vävrvnen T, Falconer C. Nordic Transvaginal Mesh Group. Trocar-guided transvaginal mesh repair of pelvic organ prolapse. Obstet Gynecol. 2009, 113, 117-126.

13. Collopy BT, Barham KA. Abdominal colporectopexy with pelvic cul-de-sac closure. Dis Colon Rectum. 2002, 45, 522-529.

14. Berglass $S$, Rubin IC. Histologic study of the pelvic connective tissue. Surg Gynecol Obstet. 1957, 97, 277-289.

15. Mercer-Jones MA, Sprowson A, Varma JS. Outcome after transperineal mesh repair of rectocele: a case series. Dis Colon Rectum. 2004, 47, 864-868. 